\title{
Lung function abnormalities and respiratory muscle weakness in children with juvenile chronic arthritis
}

\author{
L.M.E. Knook*, I.M. de Kleer*, C.K. van der Ent ${ }^{+}$, J.J. van der Net", B.J. Prakken*, W. Kuis*
}

Lung function abnormalities and respiratory muscle weakness in children with juvenile chronic arthritis. L.M.E. Knook, I.M. de Kleer, C.K. van der Ent, J.J. van der Net, B.J. Prakken, W. Kuis. (C)ERS Journals Ltd 1999.

ABSTRACT: In contrast to adult rheumatoid arthritis (RA) little is known about the prevalence, nature and cause of lung function abnormalities in children with juvenile chronic arthritis (JCA). The aim of this study was to determine whether children with polyarticular and systemic onset JCA have lung function abnormalities and if so, whether they are related to pulmonary disease, thoracic and/or muscular involvement.

We determined lung function and disability in 31 children with polyarticular and systemic JCA. Respiratory muscle function, thorax expansion and spine mobility were determined in the same patients, as well as in 32 matched healthy children.

Peak expiratory flow (PEF) and forced vital capacity (FVC) were significantly reduced in JCA patients, when compared to reference values. Thorax expansion and spine mobility were normal, compared to paired controls. Maximum inspiratory $(P I, \max )$ and expiratory $(P E, m a x)$ pressures were significantly reduced in patients compared to paired control subjects. A positive correlation was found between $P E$,max and FVC and PEF, an inverse correlation between expiratory pressure and disability.

In conclusion, children with polyarticular and systemic juvenile chronic arthritis show a pronounced impairment in respiratory muscle strength, severe enough to cause mild lung function abnormalities and an increase in disability-scores.

Eur Respir J 1999; 14: 529-533.

\author{
Dept of Pulmonology and *Immunology, \\ and "Physiotherapy, University Hospital \\ for Children and Youth, "het Wilhelmina \\ Kinderziekenhuis", Utrecht, the Nether- \\ lands.
}

Correspondence: W. Kuis

Dept of Paediatric Immunology of "het Wilhelmina Kinderziekenhuis"

P.O. Box 85090

3508 AB Utrecht

The Netherlands

Fax: 302505350

Keywords: Children

disability

juvenile chronic arthritis

lung function

respiratory muscle

Received: July 61998

Accepted after revision March 61999
Juvenile Chronic Arthritis (JCA) is the most common inflammatory arthropathy and one of the top five chronic illnesses in children [1]. JCA can be divided into three main subgroups based upon onset type: systemic, polyarticular, and oligoarticular [1]. Oligoarticular JCA is defined as arthritis in four or less joints, polyarticular JCA is defined as arthritis in five or more joints. Systemic JCA is characterized by daily fever spiking to more than $39^{\circ} \mathrm{C}$, in association with arthritis in one or more joints [1]. The extra-articular manifestations described in polyarticular and systemic onset JCA include lymphadenopathy, hepatosplenomegaly, polyserositis, and myocarditis [1].

There are, however, few descriptions of the development of lung disease as an extra-articular manifestation of JCA $[2,3]$. This is striking, because most other adult and childhood rheumatic disorders are well known to be associated with lung function abnormalities. In adult rheumatic arthritis (RA), for example, mild restrictive defects, diffuse interstitial lung disease, as well as pulmonary vasculitis and bronchiolitis obliterans have been described [4-10]. Furthermore, interstitial lung disease represents one of the most common features in adult connective tissue disease [11]. Also, in childhood connective tissue disease functional lung impairment has been shown, even in the absence of abnormalities on chest radiographs $[12$, 13]. In patients with polyarticular and systemic onset JCA, both multi-organ diseases, acute pneumonitis and pleuritis sometimes related to methotrexate (MTX)-the- rapy, have been described [14-17]. However, proper data on lung function in patients with stable polyarticular and systemic JCA are still lacking. Even more, a confusing picture has emerged regarding the prevalence, nature and cause of abnormal lung function in these patients.

In this study the authors questioned whether there are lung function abnormalities in patients with polyarticular or systemic JCA, and if so, whether this is due to primary pulmonary disease, or to an impaired mobility of the thorax and/or respiratory muscle weakness [18-21].

\section{Methods}

\section{Study population}

Thirty-two patients, 23 diagnosed as having polyarticular onset JCA (17 females, 6 males) and 9 diagnosed as having systemic onset JCA ( 5 females, 4 males) were enrolled onto the study. All patients were diagnosed according to juvenile rheumatoid arthritis (JRA)-criteria [22]. The medical records of all patients were retrospectively evaluated. Age of onset and history of treatment were recorded. Cumulative dose (oral and/or intramuscular) and duration of MTX treatment were calculated. Physical examination was performed in all children by the same examiner using a standard protocol. Informed consent was obtained from all children and their legal guardians. The study protocol was approved by the Dutch Committee for Medical Ethics. 


\section{Disease activity}

On the day of assessment swelling was scored over 64 joints by using the 4-point scale as proposed by Fuchs et al. [23] validated for children $(0=$ normal; $1=$ minimal swelling; $2=$ swelling within joint limits; $3=$ swelling exceeds joint limits). Inflammatory disease was considered as having active arthritis (swelling, pain, dysfunction) with an additional leukocytosis $\left(>10 \times 10^{9}\right.$ cells $\left.\cdot \mathrm{L}^{-1}\right)$ and/ or thrombocytosis $\left(>400 \times 10^{9}\right.$ cells $\left.\cdot \mathrm{L}^{-1}\right)$ and/or elevated C-reactive protein $\left(>30 \mathrm{mg} \cdot \mathrm{L}^{-1}\right)$ and/or elevated erythrocyte sedimentation rate $\left(\right.$ ESR) $\left(>20 \mathrm{~mm} \cdot \mathrm{h}^{-1}\right)$.

\section{Disability}

The level of disability was assessed by using the validated Dutch translations of the Childhood Health Assessment Questionnaire for parents and children (CHAQ) [24] and the Juvenile Arthritis Functional Assessment Scale (JAFAS) [25]. For both instruments, the best performance is reflected by the lowest score.

\section{Lung function}

In all patients, forced vital capacity (FVC), forced expiratory volume in one second (FEV1) and peak expiratory flow (PEF) were obtained from maximum expiratory flow volume measurements, using a pneumotachometer system (Masterlab, Jaeger, Würzburg, Germany). Best values of at least three technically well performed flow-volume curves were used. Total lung capacity (TLC) and residual volume (RV) were measured using standardized body plethysmography (Masterlab, Jaeger) in children aged $\geq 8$ yrs $(n=15)$. Reference values according to ZAPLETAL et al. [26] were used. Carbon monoxide diffusing capacity of the lung $(D \mathrm{~L}, \mathrm{CO})$ and $D \mathrm{~L}, \mathrm{CO} /$ alveolar volume $(V \mathrm{~A})$ were determined using a standardized single breath technique (Masterlab, Jaeger). Reference values from the European Community for Steel and Coal (for DL,CO) [27] and reference values obtained in a Dutch population of healthy children aged 6-18 (for $D \mathrm{~L}, \mathrm{CO} / \mathrm{VA}$ ) were used [28].

\section{Respiratory muscle function}

Respiratory muscle strength was assessed in all patients by measuring maximum static respiratory mouth pressures with a tube mouthpiece attached to a pressure gauge ( $P \max$ Monitor; Morgan Ltd., UK). The mouth pressure meter measures absolute peak pressure $(P \max )$ both for inspiratory and expiratory efforts, maximum inspiratory pressure $(P \mathrm{I}, \mathrm{max})$ and maximum expiratory pressure $(P \mathrm{E}, \max )$ respectively $[29,30]$. The $P$ I, max was measured by having the child exhale to near RV followed by a maximal inhalation effort. The PE,max was measured by having the child inhale to near TLC followed by a maximal exhalation effort. Each of the children performed at least three measurements. The highest value obtained was reported.

\section{Thorax expansion}

Maximal thorax expansion was measured in all patients and was defined as the difference in centimetres between maximal inspiration and maximal expiration measured on axillar and xiphoid level.

\section{Spine mobility}

Spine mobility was measured in all patients by means of spine flexion and extension on jugular and xiphoid level. Maximal extension and flexion, measured by inclinometry (Body Bow, Nieuwegein, the Netherlands), were determined on the first thoracic vertebra (T1), the first lumbar vertebra (L1) and the sacral vertebrae (S) and expressed in angular degrees. Thoracic spine extension and flexion is defined as the angular displacement between the T1 and L1 in extension and flexion, lumbar spine extension and flexion as the angular displacement between $\mathrm{T} 1$ and $\mathrm{S}$ in extension and flexion.

\section{Paired controls for respiratory muscle function, thorax expansion and spine mobility}

Considering lack of reference values for respiratory muscle strength, thorax expansion and spine mobility, 32 children were selected from a group of 187 healthy children, assembled in two primary schools and one secondary school. These children were accurately one to one matched with the 32 JCA patients for sex, age, length, and weight, respectively (table 1). None of these paired control subjects were under medical care. The same examiner using a standard protocol examined the 32 paired control subjects once. Informed consent was obtained from all children and their legal guardians.

\section{Statistical analysis}

All variables were presented as mean \pm SD. The lung function test results were compared with predicted values using a paired samples t-test. Differences between patients and paired controls were analysed with a paired samples ttest. Spearman rank correlation coefficients were used to explore relationships between lung function, respiratory muscle function, disability scores and MTX treatment. When calculating correlation, lung function was expressed as a percentage of the predicted value (\% pred.) to correct for age and sex. To correct for multiple comparisons a fixed $\alpha=0.01$ Bonferroni correction was used. All normally distributed continuous values were assessed with t-test.

\section{Results}

\section{Study population}

One matched pair was excluded from analysis because the patient was not able to perform lung function and mouth pressure measurement due to a severe impairment of the temporo-mandibular joint. (Characteristics of the study population are shown in table 1 ). The remaining 31 patients were on antirheumatic medication. Three patients had a history of either asthma or chronic bronchitis. Three patients had a history of acute pneumonitis.

\section{Disease activity and disability}

Joint disease, inflammatory disease, functional and health assessment outcomes are presented as characteristics of the study population (table 1). In the subgroup of 
Table 1. - Characteristics of the study population

\begin{tabular}{lcc}
\hline & Patients & $\begin{array}{c}\text { Paired } \\
\text { control } \\
\text { subjects }\end{array}$ \\
\hline Number & & 31 \\
Poly-articular JCA & 31 & \\
Systemic JCA & 23 & 71 \\
Female \% & 8 & $9.7 \pm 4.3$ \\
Age yrs* & 71 & \\
Length m* & $9.7 \pm 3.9$ & $1.41 \pm 0.23$ \\
Weight kg* & $36.4 \pm 14.8$ & $34.7 \pm 13.8$ \\
Ethnicity & & \\
Caucasian & 29 & 30 \\
Mediterranean & 2 & \\
African & & \\
Serological characteristics & $14 / 31$ & \\
ANA positive & \\
RF positive & $2 / 31$ & \\
HLA-B27 positive & $0 / 31$ & \\
Medication & & \\
MTX & $12 / 31$ & \\
Current use & $9 / 31$ & \\
Cumulative dose mg* & & \\
Duration weeks* & & \\
Prednisone current & $1443.6 \pm 787.8$ & \\
Iridocyclitis & $115 \pm 55.3$ & \\
Disease activity & $10 / 31$ & \\
Joint count Fuchs scale 23$]^{*}$ & $2 / 31$ & \\
Duration of disease yrs* & $0.7 \pm 1.2$ & \\
Active disease & $4.4 \pm 2.6$ & \\
Disability & $6 / 31$ & \\
JAFAS n=23* & & \\
normal range: 0-20 & & \\
CHAQ & & \\
normal range: 0.0-3.0 & & \\
parental form n=31* \\
child form n=23* & & \\
\hline
\end{tabular}

JCA: juvenile chronic arthritis; ANA: antinuclear antibody; RF: rheumatoid factor; HLA-B27: human leukocyte antigen-B27; MTX: methotrexate; JAFAS: juvenile arthritis functional assessment scale; CHAQ: childhood health assessment questionnaire. *: mean $\pm \mathrm{SD}$; $: 13$ patients with polyarticular JCA, 1 patient with systemic JCA; ${ }^{*}$ defined as having active arthritis (swelling, pain, dysfunction) with an additional leukocytosis and/or thrombocytosis and/or elevated CRP and/or elevated erythrocyte sedimentation rate.

12 children using MTX, a significant positive correlation $(\mathrm{p}<0.01)$ was found between duration of MTX therapy and the JAFAS $(\alpha=0.87)$, indicating that long-term MTX treatment is associated with disease activity and disability.

\section{Lung function}

Lung function results are presented in table 2. FVC and PEF were significantly lower than reference values. Furthermore, a significant increase in FEV1/FVC and DL,CO/ $V \mathrm{~A} D \mathrm{~L}, \mathrm{CO}$, was found FEV1 and TLC were not significantly different from reference values. The reductions in FVC and PEF were not related to age or sex. Analysis of the subgroups showed that there were no significant differences in lung function between patients with or without previous or current MTX therapy, systemic and polyarticular JCA patients, and patients with or without
Table 2. - Results of lung function tests

\begin{tabular}{lcc}
\hline & Patients & $\begin{array}{c}\text { Mean reference } \\
\text { values }\end{array}$ \\
\hline TLC L $(\mathrm{n}=20)$ & $3.75 \pm 1.38$ & $3.89 \pm 1.12$ \\
FVC L $(\mathrm{n}=30)$ & $2.34 \pm 1.07^{*}$ & $2.50 \pm 1.02$ \\
PEF L $\cdot \mathrm{s}^{-1}(\mathrm{n}=30)$ & $4.52 \pm 1.79^{*}$ & $4.85 \pm 1.63$ \\
$\mathrm{FEV1} \mathrm{L}(\mathrm{n}=30)$ & $2.14 \pm 1.02$ & $2.12 \pm 0.84$ \\
$\mathrm{FEV} 1 / \mathrm{FVC} \%(\mathrm{n}=30)$ & $93 \pm 9^{\#}$ & $85 \pm 4$ \\
$\begin{array}{l}\mathrm{DL}, \mathrm{CO} / \mathrm{VA}(\mathrm{n}=18) \\
\mathrm{mmol} \cdot \mathrm{min}^{-1} \cdot \mathrm{kPa}^{-1} \cdot \mathrm{L}^{-1}\end{array}$ & $2.10 \pm 0.45^{\#}$ & $1.78 \pm 0.27$ \\
$\begin{array}{l}\mathrm{DL}, \mathrm{CO}(\mathrm{n}=20) \\
\mathrm{mmol} \cdot \mathrm{min}^{-1} \cdot \mathrm{kPa}^{-1}\end{array}$ & $7.76 \pm 1.98$ & $7.15 \pm 1.50$ \\
\hline
\end{tabular}

Data are presented as mean \pm SD. Significance was calculated using paired samples t-tests, compared to predicted values; *: $\mathrm{p}<0.05$ (decrease); $: \mathrm{p}<0.01$ (decrease); $\#: \mathrm{p}<0.01$ (increase).

disease activity. A significant inverse correlation $(\mathrm{p}<0.01)$ was found between lung function (FVC, PEF) and disability score (CHAQ) outcome in patients $(\alpha=-0.60$, and $\alpha=-0.59$, respectively).

\section{Respiratory muscle function}

$P \mathrm{I}$,max and $P$ E,max were significantly lower in patients compared to paired controls (table 3 ). A positive correlation was found between respiratory muscle function in expiration $(P E, \max )$ and $\mathrm{FVC}$ and $\mathrm{PEF}(\alpha=0.37, \mathrm{p}<0.05$, (fig. 1); $\alpha=0.34, \mathrm{p}=0.06$, respectively). An inverse correlation was found between disability score (JAFAS) and $P$ E, $\max (\alpha=-0.48, \mathrm{p}<0.05)$. Furthermore, in the 12 children using MTX, an inverse correlation was found between duration of MTX treatment and PI,max $(\alpha=-0.65) /$ $P$ E, max $(\alpha=-0.58)$.

\section{Thorax expansion and spine mobility}

No differences between patients and paired control subjects were found for thoracic extension, flexion, and expansion, nor in lumbar extension and flexion (table 3).

Table 3. - Respiratory muscle function, thorax expansion and spine mobility in patients compared to paired control subjects

\begin{tabular}{|c|c|c|}
\hline & Patients & $\begin{array}{l}\text { Paired } \\
\text { controls }\end{array}$ \\
\hline \multicolumn{3}{|c|}{ Respiratory muscle function $\mathrm{cmH}_{2} \mathrm{O}$} \\
\hline$P \mathrm{I}, \max (\mathrm{n}=29)$ & $62 \pm 24 *$ & $73 \pm 27$ \\
\hline$P \mathrm{E}, \max (\mathrm{n}=31)$ & $74 \pm 31^{\#}$ & $96 \pm 34$ \\
\hline Thorax expansion $\mathrm{cm}(\mathrm{n}=30)$ & $0.45 \pm 2.64$ & $0.30 \pm 1.62$ \\
\hline \multicolumn{3}{|l|}{ Spine mobility (angular degrees) } \\
\hline \multicolumn{3}{|l|}{ Flexion $(\mathrm{n}=31)$} \\
\hline thorax & $73.5 \pm 15.8$ & $78.1 \pm 12.6$ \\
\hline lumbar & $15.3 \pm 8.5$ & $17.4 \pm 8.1$ \\
\hline \multicolumn{3}{|l|}{ Extension $(\mathrm{n}=31)$} \\
\hline thorax & $21.7 \pm 14.8$ & $17.8 \pm 14.6$ \\
\hline lumbar & $30.6 \pm 16.4$ & $24.7 \pm 12.2$ \\
\hline
\end{tabular}

Data are presented as mean $\pm \mathrm{SD}$. $P \mathrm{I}$,max: maximal inspiratory pressure; $P$ E,max: maximal expiratory pressure. Significance was calculated using paired samples t-tests; *: $\mathrm{p}<0.05$; $^{\#}: \mathrm{p}<0.01$. 


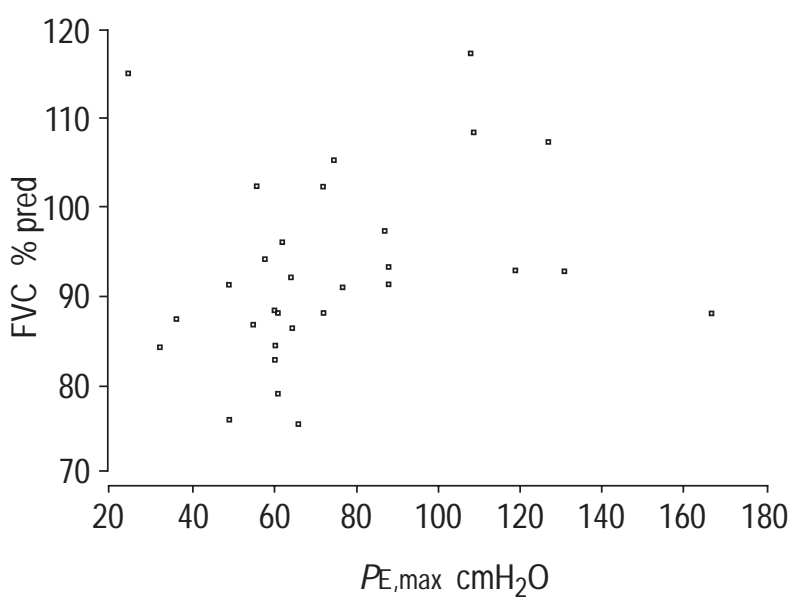

Fig. 1. - Correlation between lung function and expiratory muscle strength. Scatterplot of the correlation between forced vital capacity (FVC\% pred.) and expiratory muscle strength (expressed as maximal expiratory pressure $(P \mathrm{E}, \max )) ; \mathrm{a}=0.37, \mathrm{p}<0.05$. The result for one patient has been eliminated due to poor reliability.

\section{Discussion}

In this study it has been demonstrated that children with systemic and polyarticular JCA show a mild impairment in lung function (FVC and PEF). In contrast to what is shown in adult rheumatic arthritis an indication for restrictive or obstructive pulmonary dysfunction was not found in patients with JCA, since TLC and FEV1 were normal and the diffusion capacity, as measured by $D \mathrm{~L}, \mathrm{CO}$ and $D \mathrm{~L}, \mathrm{CO} /$ $V$ A was not decreased. The absence of evidence for intrapulmonary restrictive or obstructive disease implied an extra-pulmonary origin for the abnormal lung functions in the patient group; either impairment in thorax and/or spine mobility and/or a weakness of the respiratory muscles.

An impairment of thoracic and/or spine mobility has been suggested to reduce thorax excursion, resulting in a tendency to develop lung function abnormalities [12, 21]. Thus far, this had not been studied in patients with JCA. It has now been demonstrated that there is no impairment in thorax and spine mobility related to lung function in patients with JCA. In evaluating respiratory muscle function, however, a pronounced impairment in respiratory muscle strength was found, as measured by $P E$,max and $P \mathrm{I}, \mathrm{max}$, even in patients with no clinically evident thoracic and/or spine involvement. The impairment in expiratory muscle strength was indeed correlated to a decreased lung function (FVC and PEF). This relationship between respiratory muscle strength and lung function abnormalities in JCA makes sense. It is well known that FVC, PEF, $P$ E, max and $P \mathrm{I}, \max$ are all effort-dependent tests. In a previous study, decreases in FVC following exercise with corresponding decrements in $P$ E,max have been suggested to be a result of respiratory muscle fatigue with a reduced ability to exhale to residual volume, thus exhibiting a reduced FVC [31]. Furthermore, in a study on muscle function in children with JCA a pronounced general muscle weakness was found [32]. STRANO et al. [33] found a reduced muscular mass in association with nutritional deficiencies in children with JCA. Nutritional deficiencies might indeed be an independent factor in the outcomes of the current study. Body-composition was not measured in this study, but for respiratory muscle strength assessment all patients were tightly matched in height and weight to healthy children. Since the study population had a normal height and weight according to reference percentiles [28], nutritional deficiencies may not be a major factor influencing the lung function outcome. No adverse relationship was found between any of the lung function parameters and the cumulative dose and/or duration of MTX therapy. This finding is in agreement with a prior study, in which the authors found no pulmonary side effects of MTX therapy in children with JCA [17]. It was found that in the 12 children using MTX, long-term treatment was associated with a decreased respiratory muscle function. This might be explained by the following: longterm MTX treatment is likely to be associated with severe disease and therefore it is highly probable that this is in fact associated with the decreased respiratory muscle function. The limited number of children with current inflammatory disease and the relatively low mean JAFAS and CHAQ scores, reflects a group of patients with a currently mild disease activity and mild functional disability at the moment of assessment. However, the considerable number of patients still using MTX $(29 \%)$ and prednisone $(32 \%)$ implies that many of the patients studied had a history of severe disease activity. While no statistically significant relationships were found between muscle strength and long term MTX treatment, it cannot be excluded that it is the overall disease activity that is associated with disability and abnormalities in lung function.

Noteworthy at this point is that relationships were found between disability score (CHAQ) and lung function and disability score (JAFAS) and expiratory mouth pressure. Respiratory muscle weakness may thus result in a condition of impaired lung function in combination with a growing impairment of the functional capacity of the patient. This might imply that in children with JCA, a cycle of pain, stiffness and decreased activity leads to poor fitness and generalized muscle weakness, expressed by lung function abnormalities and an increase of the patient's disability. Recently SAAG et al. [9] reported similar results in adults.

In conclusion, a pronounced impairment was found in respiratory muscle strength in children with systemic and polyarticular juvenile chronic arthritis, severe enough to cause mild lung function abnormalities and an increase in disability. Although muscle strength is not the only condition that influences lung function, this condition is presumably important to the child. Exercise programmes for children with juvenile chronic arthritis have been prescribed routinely by physical therapists, improving range of motion, muscle strength and cardiovascular endurance [34]. Furthermore, high-intensity strength training is feasible and safe in patients with rheumatoid arthritis, and is a way to improve strength, and decrease pain and fatigue without exacerbating disease activity or joint pain [35]. Hence muscle strength can be trained and in this way a reduction of the child's functional capacity might be prevented.

Acknowledgements. The authors thank M. DiederikZwijnenburg and W. Baars-de Gier for their invaluable technical support and effort in obtaining the lung function test results. The authors would also like to thank R.E. Petty for the English correction of the manuscript and I.J.A.J. Faber for statistical assistance. 


\section{References}

1. Cassidy JT, Petty RE. Textbook of Pediatric Rheumatology, 3rd ed. Philadelphia, W.B. Saunders, 1995.

2. Pelluchi A, Lomater C, Gerloni V, Foresi A, Fantini F, Marazzini L. Lung function and diffusion capacity for carbon monoxide in patients with juvenile chronic arthritis: effect of disease activity and low dose methotrexate therapy. Clin Exp Rheumatol 1994; 12: 675-679.

3. Wagenar JS, Tassig LM, De Benedetti C, Lemen RJ, Loughlin GN. Pulmonary function in juvenile rheumatoid arthritis. J Pediatr 1981; 99: 108-110.

4. Carson C, Cannon GW, Egger MJ, Ward J, Clegg DO. Pulmonary disease during treatment of rheumatoid arthritis with low dose pulse methotrexate. Semin Arthritis Rheum 1987; 16: 186-195.

5. Hargreaves MR, Mowat GA, Benson MK. Acute pneumonitis associated with low dose methotrexate treatment for rheumatoid arthritis. Thorax 1992; 47: 628-633.

6. Engelbrecht JA, Calhoon SL, Scherrer JJ. Methotrexate pneumonitis after low-dose therapy for rheumatoid arthritis. Arthritis Rheum 1983; 26: 1275-1278.

7. Banks J, Banks C, Cheong B, Umachandran V, Smith AP, Jessop JD, Pritchard MH. An epidemiological and clinical investigation of pulmonary function and respiratory symptoms in patients with rheumatoid arthritis. $Q \mathrm{~J} \mathrm{Med}$ 1992; 307-308: 795-806.

8. Dayton CS, Schwartz A, Sprince NL, Yagla SJ, Davis CS, Koehnke RK, et al. Low-dose methotrexate may cause air trapping in patients with rheumatoid arthritis. Am J Crit Care Med 1995; 151: 1189-1193.

9. Saag KG, Kolluri S, Koehnke M, Georgou TA, et al. Rheumatoid arthritis lung disease. Arthritis Rheum 1996; 39: 1711-1719.

10. Hacking JC, Flaver CDR. Causes and investigation of increasing dyspnoea in rheumatoid arthritis. Ann Rheum Dis 1995; 54: 17-19.

11. Derderian SS, Tellis CJ, Abbrecht FCPM, Welton RC, Rajagopal KR. Pulmonary involvement in mixed connective tissue disease. Chest 1985; 88: 45-48.

12. Cerveri I, Bruschi C, Ravelli A. Pulmonary function in childhood connective tissue disease. Eur Respir J 1992; 5: 733-738.

13. Tiddens HAWM, van der Net JJ, de Graeff-Meeder ER, et al. Juvenile-onset mixed connective tissue disease: Longitudinal follow-up. J Pediatr 1993; 122: 191-197.

14. Athreya BH, Doughty RA, Bookspan M, Shumacher M, Sewell EM, Chatten J. Pulmonary manifestations of juvenile rheumatoid arthritis. Clin Chest Med 1981; 1: 361.

15. Lovell D, Lindsley C, Langston C. Lymphoid interstitial pneumonia in juvenile rheumatoid arthritis. $J$ Pediatr 1984; 105: 947.

16. Rose CD, Singsen BR, Eichenfield AH, Goldsmith DP, Athreya BH. Safety and efficacy of methotrexate therapy for juvenile rheumatoid arthritis. J Pediatr 1990; 117: 653-659.

17. Graharn LD, Myones BL, Rivas-Chacon RF, Pachman LM. Morbidity associated with long-term methotrexate therapy in juvenile rheumatoid arthritis. $J$ Pediatr 1992; 120: 468-473.

18. Hakonarson H, Moskovitz J, Daigle KL, Cassidy SB, Cloutier MM. Pulmonaty function abnormalities in Prader-Willi syndrome. J Pediatr 1995; 126: 565-570.

19. O'Donohue WJ, Baker JP, Bell GM. Respiratory failure in neuromuscular disease. JAMA 1976; 235: 733-736.

20. Begin R, Bureau MA, Lupien L. Pathogenesis of respiratory insufficiency in myotonic dystrophy. Am Rev Respir Dis 1982; 125: 312-318.

21. Kearon C, Viviani GR, Kirkley A, Killian KJ. Factors determining pulmonary function in adolescent idiopathic scolioses. Am Rev Respir Dis 1993; 148: 288-294.

22. Brewer EJ, Bass J, Baum J, Cassidy JT, et al. Current proposed revision of JRA-criteria. Arthritis Rheum 1977; 20: 195.

23. Fuchs HA, Callahan LF, Kaye JJ. Radiographic and joint count findings of the hand in rheumatoid arthritis. Arthritis Rheum 1988; 31: 44-51.

24. Singh G, Athreya B, Fries J, Goldsmith DP, Ostrov BE. Measurements of health status in children with juvenile rheumatoid arthritis. Arthritis Rheum 1994; 37: 17611769.

25. Lovell DJ, Howe S, Shear E. Development of a disability measurement tool for juvenile rheumatoid arthritis - the juvenile functional assesment scale. Arthritis Rheum 1989; 32: 1390-1395.

26. Zapletal A, Samanek M, Paul T. Upstream and total airway conductance in children and adolescents. Bull Eur Physiopathol Resp 1982; 18: 31-37.

27. Cotes JE, Chinn DJ, Quanjer PhD, Roca J, Yernault JC. Standardization of the measurement of transfer factor (diffusion capacity). Eur Respir J 1993; 6: 41-52.

28. Stam H, Hrachovina V, Stijnen T, Versprille A. Diffusion capacity dependent lung volume and age in normal subjects. J Appl Physiol 1994; 76: 2356-2363.

29. Sobush DC, Dunning M. Assessing maximal static ventilatory muscle pressures using the "Buggle" dynamometer. Phys Ther 1984; 64: 1689-1690.

30. Hamnegard CH, Wragg S, Kyroussis D, Aquillina R, Moxham J, Green M. Portable measurement of maximum mouth pressures. Eur Respir J 1994; 7: 398-401.

31. O'Kroy JA, Loy RA, Coast JR. Pulmonary function changes during exercise. Med Sci Sports Exerc 1992; 72: 365-372.

32. Lindehammer H, Backman E. Muscle function in juvenile chronic arthritis. J Rheumatol 1995; 22: 1159-1165.

33. Strano CG, Polito C, Alessio M, et al. Nutritional status in active juvenile chronic arthritis not treated with steroids. Acta Paediatr 1995; 84: 1010-1013.

34. Giannini MJ, Protas EL. Exercise response in children with and without juvenile rheumatoid arthritis. Phys Ther 1992; 72: 365-372.

35. Rall LC, Nikbin Meydani S, Kehayias JJ, DawsonHughes B, Roubenoff R. The effect of progressive resistance training in rheumatoid arthritis. Arthritis Rheum 1996; 39: 415-426. 